\title{
AS TECNOLOGIAS INFORMACIONAIS E OS EXCLUÍDOS DIGITAIS DA AMAZÔNIA: O PAPEL DA JURISDIÇÃO NA CONSECUÇÃO DE DIREITOS
}

\author{
Bruno Mello Corrêa de Barros* \\ Daniela Richter** \\ Patrícia dos Reis ${ }^{* * *}$
}

SUMÁRIO: Introdução; 2 A Sociedade Informacional e a Sustentabilidade Ambiental: a interface da Jurisdição na promoção de um Meio Ambiente ecologicamente equilibrado; 3 O Desafio do Uso das Tecnologias Informacionais pelos Excluídos Digitais: um olbar sobre o prisma do Ciberativismo na Amazônia; 4 Conclusão; Referências.

RESUMO: O ensaio tem como viés principal analisar a interface existente entre as Tecnologias Informacionais e a sustentabilidade ambiental, os eixos tecnológicos que as conectam e que podem propiciar medidas necessárias para um desenvolvimento sustentável através do acesso à informação. Ademais, pretende-se explanar a respeito dos excluídos digitais, àqueles que não utilizam da Internet ou que a ela não possuem acesso, bem como questionar o papel da jurisdição na consecução de um meio ambiente ecologicamente equilibrado. Nesse ínterim, como aporte metodológico utilizou-se o método de abordagem dedutivo, propiciando uma visão ampla acerca da revolução informacional e das TICs como instrumentos necessários à efetivação da sustentabilidade através do amplo e irrestrito acesso à informação, ainda, da jurisdição na consecução do direito a um meio ambiente sustentável, já quanto ao método de procedimento, utilizou-se do procedimento monográfico ou de estudo de caso, vislumbrando os excluídos digitais, localizados no Norte e Nordeste do país.

PALAVRAS-CHAVE: Direitos; Excluídos Digitais; Jurisdição; Sustentabilidade; Tecnologias.

\section{INFORMATIONAL TECHNOLOGIES AND THE DIGITALLY EXCLUDED IN THE AMAZON REGION: THE ROLE OF LAW TO PURSUE RIGHTS}

ABSTRACT: The interface between Informational Technologies and Environmental

\footnotetext{
" Mestrando em Direito pelo Programa de Pós-Graduação em Direito (PPGD) da Universidade Federal de Santa Maria (UFSM), Brasil. Bolsista CAPES. E-mail: brunomellocbarros@gmail.com

* Doutora em Direito pelo Programa de Pós-Graduação em Direito (PPGD) da Universidade Federal de Santa Catarina (UFSC); Docente do Curso de Direito de FAMES e UNIFRA, Brasil.

*** Mestranda em Direito pelo Programa de Pós-Graduação em Direito (PPGD) da Universidade Federal de Santa Maria (UFSM), Brasil.
} 
Sustainability, the connecting technological axes, and the factors required for the sustainable development through access to information are analyzed. Digitally excluded people, or rather, those who do not use the Internet or who do not have access to it, and the role of the law to achieve an ecologically balanced environment are discussed. The deductive approach is employed based on a perspective on the information revolution and on TICs as necessary tools for the effectiveness of sustainability through a wide and unlimited access to information as a right for sustainable environment. Methodology comprises a case study on digitally excluded people in the northern and northeastern regions of Brazil.

KEY WORDS: Technology; Sustainability; Jurisdiction; digitally excluded people; Rights.

\section{LAS TECNOLOGÍAS INFORMATIVAS Y LOS EXCLUÍDOS DIGITALES DE AMAZONÍA: EL PAPEL DE LA JURISDICCIÓN EN LA CONSECUCION DE DERECHOS}

RESUMEN: El ensayo tiene como objetivo analizar la interfaz existente entre las Tecnologías Informativas y el sostenimiento ambiental, los ejes tecnológicos que las conectan y que pueden propiciar medidas necesarias para el desarrollo sostenible por medio del acceso a la información. Además, se pretende explanar respecto a los excluidos digitales, aquellos que no utilizan Internet o que no tienen acceso a ella, bien como cuestionar el papel de la jurisdicción en la consecución de un medio ambiente ecológicamente equilibrado. En ese proceso, como aporte metodológico se ha utilizado el método de abordaje deductivo, propiciando una visión amplia sobre la revolución informacional y las TICs como instrumentos necesarios a la efectividad de la sostenibilidad a través del amplio e irrestricto acceso a la información, aún, de la jurisdicción en la consecución del derecho a un medioambiente sostenible, ya en relación al método de procedimiento, se ha utilizado del procedimiento monográfico o estudio de caso, vislumbrando los excluidos digitales, ubicados en el Norte y Nordeste del país.

PALABRAS-CLAVE: Tecnologías; Sostenibilidad; Jurisdicción; Excluidos Digitales; Derechos.

\section{INTRODUÇÃO}

O desenvolvimento tecnológico e científico promoveu profundas transformações na atual sociedade. Aliados a esses fatores, os avanços da economia 
e das telecomunicações permitiram a formação de uma sociedade complexa, a qual exige respostas e soluções rápidas. As Tecnologias da Informação e Comunicação, especialmente aquelas ligadas à Internet, corroboram para esse espectro, garantindo que uma ampla camada de setores e atividades possam delinear-se na contemporaneidade.

Nesse sentido, partindo do pressuposto das tecnologias informacionais, diversos Estados desenvolveram estratégias de modo a levar os seus cidadãos a ter acesso a dados públicos de caráter relevante e a possibilidades democráticas virtuais, consistindo aí lógicas de Governo eletrônico e Teledemocracia. Tais estratégias apontam como a conectividade é exponencial e passa a guiar vida social e os governos na atualidade.

Destaca-se, nesse sentido, uma extraordinária indução aos meios tecnológicos, sopesados pela Internet, criando uma rede de indivíduos conectados e interlocutores das mais diversas demandas e pautas, sejam elas políticas, sociais ou culturais. Neste enfoque, o presente artigo pretende analisar se o amplo e irrestrito acesso à informação proporcionado pelas TICs a partir da revolução e sociedade informacional podem auxiliar na construção de um ideário comprometido com a sustentabilidade ambiental e a ecologia. Da mesma forma, pretende-se visualizar o papel da jurisdição na consecução do Direito a um meio ambiente ecologicamente equilibrado, à luz dos Direitos Fundamentais e do rol de garantias previstas na Carta da República de 1988.

Nesse ínterim, o ensaio foi delineado de modo que as pautas temáticas nele abordadas pudessem ser ancoradas a partir de dois eixos fundamentais, onde o primeiro diz respeito à sociedade informacional e à sustentabilidade ambiental. Já o segundo, deslinda-se acerca do papel da jurisdição na atualidade, como um sistema que tem o condão de efetivar direitos e promover um meio ambiente ecologicamente equilibrado, sob a ótica da Constituição e de seus mandamentos. Ademais, aborda um estudo de caso sobre os excluídos digitais da Amazônia, aquela parcela de indivíduos que encontram-se em regiões do Norte e Nordeste do país e permanecem fora do eixo informacional, visto que não há investimentos do setor público e da iniciativa privada com intuito de estabelecer conexões naquela região e estimular o acesso à Internet e às potencialidades ofertadas com a virtualidade.

Nesse contexto, pretende-se explorar a temática e oferecer a visualização acerca do Ciberativismo implementado pelos povos da floresta, o que demonstra as 
benesses e potencialidades vislumbradas com a adoção de tecnologias informacionais. Desse modo, o artigo apresenta a visualização do cenário na contemporaneidade, marcado pelas Tecnologias da Informação e Comunicação, especialmente pela interatividade proporcionada pela Internet, o paradigma da necessária efetivação do Direito a um meio ambiente ecologicamente equilibrado através da Jurisdição e o caso daqueles que ainda encontram-se à margem de todo esse contexto, fora do âmbito de participação digital, como o caso dos excluídos da Amazônia. Sobre todo esse contexto é que se passa a explanar em tópico a seguir.

\section{A SOCIEDADE INFORMACIONAL E A SUSTENTABILIDADE AMBIENTAL A INTERFACE DA JURISDIÇÃO NA PROMOÇÃO DE UM MEIO AMBIENTE ECOLOGICAMENTE EQUILIBRADO}

A utilização das Tecnologias da Informação e Comunicação - TICs ${ }^{04}$ tem perpassado diversos âmbitos a partir de sua amplitude e massificação. Deste modo, desde a Revolução Industrial, que modificou os parâmetros técnicos de produção até então existentes, vislumbrou-se um crescimento exponencial na utilização de tecnologias com o fito desenvolvimentista e comercial. Com a ampliação dos meios e estruturas de produção e comercialização econômica, sobretudo das TICs e da Internet, a transição da manufatura para produção em larga escala prospectou-se o uso material do meio ambiente como fonte geradora de matéria-prima e forte indutora de riquezas a partir daquilo que é produzido sob seus auspícios. Neste enfoque, Mattelart ${ }^{05}$ expõe que "as redes de comunicação em tempo real estão configurando o modo de organização do planeta".

Nesta égide, contudo, há uma transformação exponencial no século $\mathrm{XX}$, onde a informação, como bem imaterial, passa a ser força motriz e mola propulsora da sociedade, estabelecendo fluxos informacionais rápidos e contínuos que transcendem as barreiras do imaterial e passam a conectar diversos Estados a partir do fenômeno da globalização. Nesse paradigma tem-se o estabelecimento

\footnotetext{
${ }^{04}$ As Tecnologias da Informação e Comunicação podem ser definidas como um conjunto de recursos tecnológicos usados para produzir e disseminar informaçóes, dentre os quais estão o telefone (fixo e celular), o fax, a televisão, as redes (de cabo ou fibra óptica) e o computador, sendo que a conexão de dois ou mais computadores cria uma rede, e a principal rede existente atualmente é a Internet (SANCHES, 2003).

${ }^{05}$ MATTELART, Armand. La Mundializacíon de la comunicacíon. Tradução de Orlando Carreño. Barcelona: Paidós, 1998, p. 7.
} 
da chamada Sociedade Informacional, noção cunhada por Manuel Castells para definir as novas formas de se prospectar a vida e organização social. Sobre tal tema, Castells ${ }^{06}$ aponta que:

[...] o termo informacional indica o atributo de uma forma específica de organização social em que a geração, o processamento e a transmissão da informação tornam-se fontes fundamentais de produtividade e poder devido às novas condições tecnológicas surgidas nesse período histórico.

Com efeito, a informação e a ingerência sobre a quem a detém mostram como o poder é reverberado na sociedade hodierna, tendo, sobretudo, a informação propiciado o desenvolvimento de inúmeras mídias digitais ${ }^{07}$, visto que o imediatismo, a velocidade e a aceleração com os quais essa informação é perpassada e difundida são os corolários dessa sociedade informacional.

Nesse panorama, muitos autores visualizam e analisam negativa e positivamente o caráter das tecnologias informacionais e da Internet para consecução de direitos, acesso a determinadas garantias e também para a promoção de um meio ambiente ecologicamente equilibrado. Nesse sentido, André Volkmer ${ }^{08}$ afirma que "na história da humanidade, o poder nunca esteve tão à mão do indivíduo" e que "a Internet, provavelmente, diminuirá muito o radicalismo e aumentará o respeito aos direitos humanos, à ética e à moral” ${ }^{\circ}$. Da mesma forma, Gonçalves ${ }^{10}$ coloca que "as possibilidades técnicas de comunicação e de acesso à informação permitiram desfrutar mais plenamente os direitos e liberdades contemplados pelos regimes liberais/democráticos".

Entretanto, outros doutrinadores não concordam com as visões otimistas quanto às potencialidades das TICs e da Internet. Gilberto Dupas ${ }^{11}$ afirma que "os vetores tecnológicos autonomizaram-se definitivamente de considerações de natureza ética, social ou de políticas públicas", o resultado crescente dessas induções

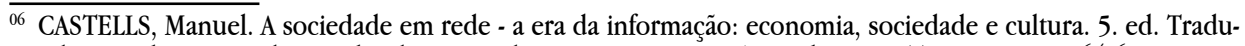
zido por Klauss Brandini Gerhardt e Roneide Venancio Majer. São Paulo: Paz e Terra, 1999, p. 64-65.

${ }^{07}$ A digitalização incrementa os intercâmbios de livros, revistas e espetáculos, mas, acima de tudo, está criando redes de conteúdos e formatos elaborados a partir da circulação midiatecnoeletrônica. Está modificando, assim, os estilos de interatividade (CANCLINI, 2008, p. 53).

${ }^{08}$ VOLKMER, André. A democracia na era digital. In: INSTITUTO DE ESTUDOS EMPRESARIAIS. Liberdade na era digital. Porto Alegre: IEE, 2011, p. 99-104.

${ }^{09}$ Ibidem, 2011, p. 104.

${ }^{10}$ GONÇALVES, Maria Eduarda. Direito da informação: novos direitos e formas de regulação na sociedade da informação. Coimbra: Almedina, 2003, p. 31.

${ }^{11}$ DUPAS, Gilberto. Ética e poder na sociedade da informação: de como a autonomia das novas tecnologias obriga a rever o mito do progresso. 2. ed. rev. ampliada. São Paulo: UNESP, 2011, p. 28-29. 
tecnológicas e informacionais seria o aumento da concentração de renda e exclusão social, especialmente para aqueles indivíduos que não possuem acesso a tais meios e à Internet. Para Pérez Luño (2004) "a realidade em transformação exige a atualização coerentes dos princípios da democracia constitucional e sua adequação aos desafios trazidos pelo progresso técnico-científico".

Mesmo questionando acerca de pontos fulcrais na contemporaneidade como, por exemplo, Cibercidadania, Governo Eletrônico, Teledemocracia e demais outras formas de interação entre a população - os cidadãos - e a Administração Pública, é unívoco reafirmar o caráter descentralizador das tecnologias informacionais, visto que, a partir da modificação das estruturas comunicativas a lógica unidirecional é transpassada, a Internet propiciou aos indivíduos a possibilidade de serem produtores, editores e difusores da informação, além da criação de instrumentos por parte do Governo para propiciar o amplo acesso a informações relevantes de caráter público como a LAI ${ }^{12}$. Assim, nesse interregno, Bernardes ${ }^{13}$ considerała que "a sociedade informacional caracterizou-se pelas transformações nos âmbitos político, econômico e cultural advindos do novo paradigma tecnológico, o qual tem por base as Tecnologias da Informação e Comunicação (TICs)".

Para ilustrar esse processo de transformação social, Castells ${ }^{14}$ esclarece que o uso das novas tecnologias e a telecomunicação passaram por três estágios distintos, quais sejam:

A automação das tarefas; as experiências de usos (nestes dois aspectos o processo de inovação tecnológica baseou-se no aprender usando); e, por fim, a reconfiguração das aplicações (usuários aprendem a tecnologia fazendo). Através dessas transformações foi possível a reconfiguração das redes e o desenvolvimento de novos domínios.

Deste modo, conforme salientado, a informação é relevante e passa a ser refratária de diversos aspectos centrais e de discussão universal, a exemplo da temática ambiental. As tecnologias informacionais e comunicativas, sobretudo as

\footnotetext{
${ }^{12}$ LAI quer dizer Lei de Acesso à Informação; traduz-se na Lei no 12.527 , de 18 de novembro de 2011, que regula o acesso a informações previsto no inciso XXXIII do art. 5o, no inciso II do §3o do art. $37 \mathrm{e}$ no $\$ 20$ do art. 216 da Constituição Federal; altera a Lei no 8.112, de 11 de dezembro de 1990; revoga a Lei no 11.111, de 05 de maio de 2005, e dispositivos da Lei no 8.159, de 08 de janeiro de 1991; e dá outras providências.

13 BERNARDES, Marciele Berger. Democracia na sociedade informacional: o desenvolvimento da democracia digital nos municípios brasileiros. São Paulo: Saraiva, 2013, p. 38.

${ }^{14}$ CASTELLS, Manuel. A sociedade em rede - a era da informação: economia, sociedade e cultura. 5 . ed. Traduzido por Klauss Brandini Gerhardt e Roneide Venancio Majer. São Paulo: Paz e Terra, 1999.
} 
quais possuem a Internet como suporte, puderam reverberar assuntos de supra importância para a malha social e à coletividade, e as redes sociais ${ }^{15}$ tornaram-se ágoras virtuais de debates e mobilizações acerca de uma determinada causa.

Não há de se olvidar a ruptura ocorrida na informação ofertada pela mídia tradicional e hegemônica, já que os meios de massa passaram a sofrer diretamente a concorrência dos canais comunicacionais perpetrados pela Internet. Entretanto, nesse jogo quem ganha é o usuário e o indivíduo que tem acesso, já que terá maior oferta de informação e esta a mais plural possível. Porém, independente do meio por qual a informação é difundida, o compromisso com a verdade deve ser pactuado, vez que "o ordenamento jurídico tutela uma informação correta, precisa, verdadeira, não-abusiva, ou seja, honesta"16.

Concernente a esse aspecto, vale referir que a indústria da informação surge quando o mundo dos negócios se dá conta de que a informação pode se transformar em um negócio cujas transações se realizam não mais com corporações e partidos mantenedores mas com duas categorias novas, os consumidores de informações e os anunciantes. A indústria da informação, entretanto, não poderia manter-se apenas com a venda de informações ao consumidor. Foi aí que entrou o outro elemento do jogo: o anunciante.

Nesta direção, tendo a noção de que a informação é de interesse coletivo (um bem maior) e que as plataformas digitais derrubam barreiras, onde a interatividade coloca em cheque os modelos unidirecionais da grande mídia, se aponta a utilização dessa informação em prol da constituição de um ideário comprometido com a sustentabilidade e a preservação dos recursos naturais.

Nas últimas décadas uma transformação tem ocorrido no sentido de se exasperar informações que dizem respeito à governança global para o desenvolvimento sustentável, evocando a participação ativa dos cidadãos a partir das informações sobre ecologia e meio ambiente devidamente recebidas. A primeira ação nesse sentido transcorreu com a Conferência das Nações Unidas sobre Meio Ambiente e Desenvolvimento, ocorrida no Rio de Janeiro no ano de 1992, da qual resultou em diversos documentos, entre eles a Declaração do Rio sobre Meio

\footnotetext{
${ }^{15}$ Redes sociais podem ser definidas como redes de comunicação marcadas por dois elementos centrais: os atores sociais (pessoas, instituições ou grupos) e as conexões, que são as interações sociais desenvolvidas nesse meio. Rede é uma metáfora para observar os padrões de conexão de um grupo social, a partir de conexões estabelecidas entre os diversos atores (RECUERO, 2009, p. 24). Blogs, Twitter, Facebook são espaços considerados por Recuero (2009, p. 25-26) como lugares de fala construídos pelos atores de forma a expressar elementos de sua personalidade ou individualidade.

${ }^{16}$ NETO, Guilherme Fernandes. Direito da Comunicação Social. São Paulo: Revista dos Tribunais, 2004, p. 99.
} 
Ambiente e Agenda 21, uma baliza primordial na preservação do meio ambiente.

Quanto à Declaração do Rio sobre Meio Ambiente (ONU, 1992) ${ }^{17}$, gestada durante a Conferência da ONU de 1992, destaca-se o Princípio 10, que assim coloca:

A melhor maneira de tratar de questões ambientais é assegurar a participação, no nível apropriado, de todos os cidadãos interessados. No nível Nacional, cada indivíduo terá acesso adequado às informações relativas ao meio ambiente de que disponham as autoridades públicas, inclusive informações acerca de materiais e atividades perigosas em suas comunidades, bem como a oportunidade de participar dos processos decisórios. Os Estados irão facilitar e estimular a conscientização e a participação popular, colocando as informações à disposição de todos. Será proporcionado o acesso efetivo a mecanismos judiciais e administrativos, inclusive no que se refere a compensação e reparação de danos.

Da mesma forma, a Agenda 21 Global, elaborada pelos países presentes na Rio-92, trata a respeito do dever dos Estados e das organizações internacionais de rever e fortalecer os sistemas e serviços de informação relacionados ao desenvolvimento sustentável nos planos local, regional, nacional e internacional. Desta feita, a informação aponta-se como a principal arma contra um sistema baseado na degradação ambiental e no extermínio dos recursos naturais.

Nos auspícios da Agenda 21 Global (ONU, 1992b) ${ }^{18}$ cumpre referir:

Deve-se ênfase especial à transformação da informação existente em formas mais úteis a tomada de decisões e em orientá-la para diferentes grupos de usuários. Devem-se estabelecer ou fortalecer mecanismos para converter as avaliações científicas e sócio-econômicas em informação adequada para o planejamento e a informação pública. Devem-se utilizar formatos eletrônicos e não-eletrônicos.

Nesse aspecto, é necessário prescrever acerca do mandamento contido no Art. 225 da Carta da República de $1988^{19}$, que assim disciplina:

Art. 225. Todos têm direito ao meio ambiente ecologicamente

$\overline{17}$ ORGANIZAÇÃO DAS NAÇÕES UNIDAS (ONU). Declaração do Rio sobre Meio Ambiente e Desenvolvimento. Publicada em 1992. Disponível em: < http://www.onu.org.br/rio20/img/2012/01/rio92.pdf. > . Acesso em: 30 mai. 2015.

${ }^{18}$ ORGANIZAÇÃO DAS NAÇÕES UNIDAS (ONU). Agenda 21 Global. Publicada em 1992. Disponível em: < http:// www.meioambiente.pr.gov.br/arquivos/File/agenda_21_Global_Integra.pdf. >. Acesso em: 30 mai. 2015.

19 BRASIL. Constituição (1988). Constituição da República Federativa do Brasil: promulgada em 05 de outubro de 1988. Brasília: Senado Federal. Disponível em: < http://www.planalto.gov.br/ccivil_03/constituicao/constituicaocompilado.htm>. Acesso em: 31 mai. 2015. 
equilibrado, bem de uso comum do povo e essencial à sadia qualidade de vida, impondo-se ao Poder Público e à coletividade o dever de defendê-lo e preservá-lo para as presentes e futuras gerações.

$\S 1^{\circ}$ Para assegurar a efetividade desse direito, incumbe ao Poder Público:

I - preservar e restaurar os processos ecológicos essenciais e prover o manejo ecológico das espécies e ecossistemas;

II - preservar a diversidade e a integridade do patrimônio genético do País e fiscalizar as entidades dedicadas à pesquisa e manipulação de material genético;

III - definir, em todas as unidades da Federação, espaços territoriais e seus componentes a serem especialmente protegidos, sendo a alteração e a supressão permitidas somente através de lei, vedada qualquer utilização que comprometa a integridade dos atributos que justifiquem sua proteção;

IV - exigir, na forma da lei, para instalação de obra ou atividade potencialmente causadora de significativa degradação do meio ambiente, estudo prévio de impacto ambiental, a que se dará publicidade;

V - controlar a produção, a comercialização e o emprego de técnicas, métodos e substâncias que comportem risco para a vida, a qualidade de vida e o meio ambiente;

VI - promover a educação ambiental em todos os níveis de ensino e a conscientização pública para a preservação do meio ambiente;

VII - proteger a fauna e a flora, vedadas, na forma da lei, as práticas que coloquem em risco sua função ecológica, provoquem a extinção de espécies ou submetam os animais a crueldade.

Desta feita, a Constituição da República consiste no referencial normativo primeiro, constituindo-se no fundamento de validade material e formal do sistema, assim, todos os dispositivos e interpretações possíveis devem passar pelo seu controle formal e material, não podendo, desta forma, ser infringida ou modificada ao talante dos representantes das instituições ou mesmo da vontade da maioria.

Assim, toda a decisão jurisdicional deve obedecer os paradigmas constitucionais e democráticos, como diretriz basilar, de modo a garantir a consecução de direitos, sobretudo os fundamentais, de modo que "ao Direito (e à Jurisdição) não cabe seguir as marcas da maximização da riqueza, onde a racionalidade jurídica foi substituída pela lógica da mercadoria e dos custos/benefícios" ${ }^{20}$. Deve-se estabelecer

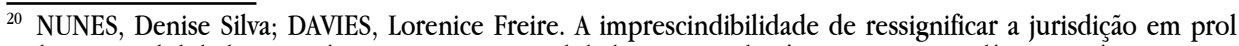
da sustentabilidade: estratégias contra a racionalidade. Revista Eletrônica Direito e Política, Itajaí, v. 10, n. 1, edição especial de 2015. Disponível em: < http://www.univali.br/direito e política > . Acesso em: 30 mai. 2015, p. 416.
} 
uma jurisdição com compromisso assumido com o próprio Estado Democrático de Direito, para além de um simples mecanismo de solução de controvérsias.

Nesse sentido, cumpre explicitar os ensinamentos de Espíndola ${ }^{21}$ :

[...] refutar o modelo normativismo-legalista, bem como o modelo do funcionalismo jurídico, em nome de uma perspectiva polarizada no homem-pessoa, sujeito da prática problemática-judicanda e assumindo como e reafirmação/recuperação do sentido da prática jurídica como iuris-prudentia. Daí falar-se da importância do papel e da delicada atuação do juiz para a concretização da Constituição dos direitos fundamentais.

Direito e Jurisdição devem apropriar-se cada vez mais do discurso a respeito de uma sustentabilidade efetiva, aquela que extrapola os textos normativos, mas que chega às casas e à vida do cidadão; isso vai ocorrer através da informação, das potencialidades das TICs como prementes difusores de conteúdos noticiosos e normativos, reverberando condutas benéficas ao planeta.

Portanto, não se pode olvidar do caráter determinante das Tecnologias da Informação e Comunicação, especialmente a Internet, como instrumentos da sociedade informacional, que reconfiguraram o eixo comunicacional, transformando a lógica unidirecional da grande mídia, propiciando aos indivíduos produzir, editar e disseminar informações. Nesse contexto, embora muitos autores ainda observem com certo negativismo o peso exponencial da Internet na coletividade não se pode negar sua penetração sob aqueles que têm acesso a estes meios, de modo a reconfigurar seus padrões de comportamento.

Sobre tal tema, é de se expor que a informação é força motriz na sociedade contemporânea, capaz de remodelar a malha social e coletividade, guiando-os para hábitos sustentáveis e em conformidade com os recursos naturais já em compasso de escassez. Do mesmo modo, guiados pela sustentabilidade, a Jurisdição desenvolve caminho no sentido de balizar as relações, perpassada pela égide da Constituição Federal e os Direitos Fundamentais. Nesta trajetória, a partir das demandas virtuais, as quais passam a compor o cenário das relações desenvolvidas hodiernamente, cumpre referenciar o caso daqueles que não possuem acesso aos meios virtuais, como, por exemplo, o caso dos excluídos digitais da Amazônia, que sofrem com

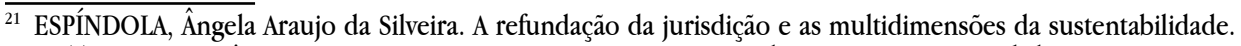
In: TYBUSCH, Jerônimo Siqueira; ARAUJO, Luiz Ernani Bonesso de; SILVA, Rosane Leal da (Org.). Direitos emergentes na sociedade global: anuário do Programa de Pós-Graduação em Direito da UFSM. Ijuí: Unijuí, 2013 , p. 426. 
a falta de incentivo por parte do Estado e da iniciativa privada em estabelecer parâmetros tecnológicos naquela região para fomentar o acesso de todos à Internet. No mesmo enfoque vislumbra-se a prática de ciberativismo realizado por tais povos na Amazônia. É sobre tal tema que se passa a destacar.

\section{O DESAFIO DO USO DAS TECNOLOGIAS INFORMACIONAIS PELOS EXCLUÍDOS DIGITAIS: UM OLHAR SOBRE O PRISMA DO CIBERATIVISMO NA AMAZÔNIA}

Antes de adentrar ao objetivo principal do presente tópico, qual seja, o uso das Tecnologias da Informação e Comunicação pelos povos amazonenses, é inerente registrar um breve apanhado histórico e geográfico desse Estado, a fim de que, no decorrer desse estudo, seja possível entender os fenômenos específicos dessa região, tendo em vista sua singularidade econômica e sociocultural.

Desse modo, registra-se que, geograficamente, a Amazônia cobre mais da metade do território nacional, sendo considerada a área de maior extensão de floresta do mundo. Com cerca de 6,9 milhões de $\mathrm{km}^{2}$, passa por nove países sulamericanos: Brasil, Bolívia, Peru, Colômbia, Equador, Venezuela, Guiana, Suriname e Guiana Francesa ${ }^{22}$. No Brasil, seu bioma atinge $4,2 \mathrm{~km}^{2}$ e atravessa os Estados do Amazonas, Pará, Mato Grosso, Acre, Rondônia, Roraima, Amapá, bem como parte de Tocantins, do Maranhão e municípios de Goiás.

Atualmente, às suas margens vivem em torno de 24 milhões de pessoas, dentre essas 342 mil indígenas das mais diversas etnias, ribeirinhos, extrativistas e quilombolas. Sua capital está localizada na cidade de Manaus ${ }^{23}$.

Ratificando o espaço geográfico, são os dados do Instituto Brasileiro de Geografia e Estatística - IBGE (2015) ${ }^{24}$ :

A Amazônia é a região compreendida pela bacia do rio Amazonas, a mais extensa do planeta, formada por $25.000 \mathrm{~km}$ de rios navegáveis, em cerca de $6.900 .000 \mathrm{~km}^{2}$, dos quais aproximadamente 3.800 .000 $\mathrm{km}^{2}$ estão no Brasil. Já a Amazônia Legal, estabelecida no artigo 2 da

$\overline{22}$ GREEANPEACE BRASIL. Amazônia: patrimônio brasileiro futuro da humanidade. Disponível em: < http:// www.greenpeace.org/brasil/pt/O-que-fazemos/Amazonia/> . Acesso em: 28 jun. 2015.

${ }^{23}$ INSTITUTO BRASILEIRO DE GEOGRAFIA E ESTATÍSTICA. IBGE. Mapa integrado dos zoneamentos ecológico-econômicos dos estados da Amazônia Legal. Disponível em: < http://www.ibge.gov.br/home/geociencias/ geografia/mapas_doc5.shtm >. Acesso em: 28 jun. 2015.

${ }^{24}$ INSTITUTO BRASILEIRO DE GEOGRAFIA E ESTATÍSTICA. IBGE. Mapa integrado dos zoneamentos ecológico-econômicos dos estados da Amazônia Legal. Disponível em: < <ttp://www.ibge.gov.br/home/geociencias/ geografia/mapas_doc5.shtm >. Acesso em: 28 jun. 2015. 
lei $\mathrm{n}^{0}$ 5.173, de outubro de 1966, abrange os estados do Acre, Amapá, Amazonas, Mato Grosso, Pará, Rondônia, Roraima, Tocantins, parte do Maranhão e cinco municípios de Goiás. Ela representa 59\% do território brasileiro, distribuído por 775 municípios [...].

Entretanto, registra-se que, durante anos, parte do que se conhece hoje na Amazônia pertencia aos espanhóis, tendo em vista o Tratado de Tordesilhas, assinado em Portugal em 1494. A primeira expedição na região amazônica ocorreu em 1637, onde mais de dois mil portugueses exploraram os seus frutos para fins comerciais. A partir de então, a mão de obra indígena, povo habitante daquele território, passou a não ser suficiente e no século XVIII chega ao Estado o povo africano.

No fim do século XIX, com o advento da Revolução Industrial, muitas fábricas passaram a operar nas terras amazônicas. Desse modo, a Inglaterra demonstrou interesse pela floresta e lá encontrou a mais importante matéria-prima extraída dos seus seringais, a borracha. Tal extração ficou conhecida como a época do Ouro Negro, tendo em vista as oportunidades de trabalho, que levou cerca de trezentos mil nordestinos para aquela região, bem como homens vindos das mais diversas partes do mundo.

Ratificando a informação, dispõe Corrêa ${ }^{25}$ :

Finalmente no século XIX, com a descoberta da vulcanização da borracha nos Estados Unidos, a partir do látex, extraído da seringueira, iniciou-se a "corrida" à Amazônia, único local de seringueiras, até então a procura de matéria-prima. Com isso estabeleceu-se, na região, empresários nacionais e estrangeiros e, ao mesmo tempo, iniciou-se o fluxo migratório de brasileiros, especialmente nordestinos, constituindo a força de trabalho nas atividades extrativas.

Já no século XX, precisamente nas décadas de 1920 a 1930, os nordestinos abandonam os seringais e voltam para suas terras de origem. A Amazônia brasileira foi então despovoada e adentrou para um novo ciclo de decadência econômica. Na década de 1940, a borracha brasileira tem uma segunda chance. Com a Segunda Guerra Mundial, os países em aliança não tinham mais acesso à matéria-prima, a qual lhes era de extrema necessidade para a indústria bélica.

Logo, foi necessária a contratação de milhares de trabalhadores a fim de atingir a produção desejada do produto. Coube então ao governo brasileiro o

${ }^{25}$ CORRÊA, Roberto Lobato. A organização regional do espaço brasileiro: redes eletrônicas e novas dinâmicas do território brasileiro. In: CASTRO; GOMES; CORREAA, 1995, p. 40. 
encaminhamento de trabalhadores para os seringais, sendo em sua grande maioria cearenses, os quais acabavam de ser atingidos por um período de prolongada estiagem e que aceitaram o convite vislumbrando um futuro promissor em meio à floresta.

Sobre a migração explana Cardoso ${ }^{26}$ :

Como se vê, o vale amazônico era tido como um espaço vazio, fonte de riquezas ainda insondáveis a espera dos braços desbravadores responsáveis pelo despertar de seu sonho edênico, transmutado a partir da labuta sistemática nos seringais em resposta à sanha da indústria internacional. A seca, portanto, torna-se a chave mestra para a discussão, pois é entendida como inerente ao processo migratório, posicionada como marco inicial do deslocamento de cearenses para a Amazônia.

Formam-se então os primeiros "povos da floresta", que apesar de dividir seu território com outras nacionalidades como a japonesa, árabe e judaica, foram os pioneiros no processo de colonização da Amazônia, instaurado por um projeto estatal e privado que visava transformar aquelas terras em um campo de trabalho e de riquezas extrativas.

Para tanto, diante do explanado histórico, verifica-se que a formação do "povo da floresta" passou por diversos períodos migratórios, todos motivados pelas terras férteis e riquezas extrativas que nelas se apresentavam com relevância a grandiosidade de seu ecossistema, vegetação e abundância de água doce, que tornavam aquele território um ambiente ecologicamente sustentável para os seus habitantes. Desse modo, hodiernamente se percebe uma diversificação de origem e cultura do povo amazonense que se distingue pela situação econômica e social.

Sobre o povoamento da Amazônia, são as palavras de Freitas ${ }^{27}$ :

As populações contemporâneas da Amazônia são compostas de grupos sociais urbanos e rurais heterogêneos do ponto de vista da situação econômica; de sociedades e comunidades indígenas de distintos e diversos modos de adaptação e articulação histórico-cultural; de grupos isolados remanescentes de fricção interétnicas e de arranjos próprios de sobrevivência com a sociedade nacional; e, ainda, de

\footnotetext{
${ }^{26}$ CARDOSO, Antônio Alexandre Isidio. Os migrantes cearenses e o horizonte amazônico no século XIX. Revista de História, v. 4, n. 1, p. 70, 2012. Disponível em: < http://www.revistahistoria.ufba.br/2012_1/a04.pdf>. Acesso em: 28 jun. 2015.

${ }^{27}$ FREITAS, Marilene Côrrea da Silva. Políticas públicas, territórios, populações tradicionais e ambiente na Amazônia. In: OLIVEIRA, José Admir de; SCHERER, Elenice (Org.). Amazônia: territórios, povos tradicionais e ambiente. Manaus: Adua, 2009, p. 23-24.
} 
grupos e contingentes populacionais deslocados pra a região por mecanismos governamentais ou promovidos por fluxos de exploração econômica ou reajustes institucionais na Amazônia.

Ademais, é importante registrar que a nomenclatura "povo da floresta", utilizada até então para definir a população amazônica, possui significado intrínseco ao objetivo principal do presente tópico, visto que ao encontro do legado deixado pelo líder ativista Chico Mendes, só pode ser chamado de "povo da floresta" aqueles que não apenas moram na Amazônia, mas aqueles que possuem uma ligação direta com os aspectos culturais, sociais e políticos daquela região ${ }^{28}$.

De acordo com Fonseca ${ }^{29}$ : "hoje Chico Mendes inspira vários ativistas da floresta (e fora dela), sua luta é símbolo de resistência e compromisso social com as populações tradicionais indígenas”. Registra-se que essa luta se materializa nas centenas de movimentos sociais que atuam na Amazônia com o intuito de transformá-la em um espaço democrático e procuram dar voz e visibilidade aos "povos da floresta", a fim de que esses possam resistir e lutar pelos seus direitos.

Destarte, vinculado ao objetivo de evidenciar esses povos como sujeitos de direitos, os movimentos sociais lutam pela inclusão digital como uma nova necessidade de articulação e desenvolvimento de saberes. Tendo em vista o ápice tecnológico e o avanço das novas Tecnologias da Informação e Comunicação - TICs, a Internet seria hoje a mola propulsora pra que os "povos da floresta" pudessem receber e disseminar informações sobre sua cultura, o seu território e assim lutar pelos seus direitos e pela proteção do meio ambiente em que vivem.

Com vistas a um conceito de inclusão digital que se enquadre a diversidade e realidade do povo amazonense, Moura ${ }^{30}$ aduz que seria "uma inclusão capaz de levar à experiência de inclusão social, abrindo caminho para que os amazônidas ditem os rumos que querem dar ao seu futuro e ao do seu território". Seria uma inclusão capaz de se fazer presente nos povos formadores da floresta e utilizar das novas TICs para ampliação e possibilidade de empoderamento de suas questões nos aspectos ambientais, econômicos e sociais.

\footnotetext{
${ }^{28}$ FONSECA, Luca Milhomens. Ciberativismo na Amazônia: os desafios da militância digital na floresta (2012). In: SILVEIRA, Sérgio Amadeu da; BRAGA, Sérgio; PENTEADO, Cláudio. Cultura, política e ativismo nas redes digitais. São Paulo: Fundação Perseu Abramo, 2014, p. 56.

${ }^{29}$ FONSECA, Luca Milhomens. Ciberativismo na Amazônia: os desafios da militância digital na floresta (2012). In: SILVEIRA, Sérgio Amadeu da; BRAGA, Sérgio; PENTEADO, Cláudio. Cultura, política e ativismo nas redes digitais. São Paulo: Fundação Perseu Abramo, 2014, p. 56.

${ }^{30}$ MOURA, Ricardo Damasceno. Múltiplos saberes da diversidade em rede: conexões interculturais no debate da inclusão digital. Inc. Soc., Brasília, v. 5, n. 2, p. 62-72, jan./jun. 2012, p. 70.
} 
Desse modo, a inclusão digital quando pensada sob a ótica da Amazônia demanda diversos enfoques que transcendem a mera instalação da rede mundial de computadores e disponibilidade de acesso à Internet, mas sim visam respeitar e proteger física, geográfica e materialmente as riquezas, os valores e os direitos do "povo da floresta" em defesa dos seus ideais.

Nesse ínterim, explana Moura ${ }^{31}$ :

Negligenciar a inclusão de comunidades tradicionais da Amazônia ao acesso às TICs é destituí-las de sua condição de sujeitos, aprofundando a desigualdade, impedindo que atores sociais se estruturem e se organizem originando novas formas de resistências coletivas contra a opressão.

Contudo, a Floresta Amazônica parece viver hoje um retrocesso ao século XIX, mais especificamente no período da Cabanagem, expressão que faz referência a uma revolta política e social que refletiu em todo o país em meados de 1835 , onde as autoridades imperiais precisaram tomar medidas violentas contra a revolta e resistência dos subordinados do império que lutavam pelos seus direitos.

A inclusão digital na Amazônia é comparada ao período acima citado, visto que o governo daquela região não apoia a implementação de cobertura digital naquelas terras alegando alto custo tornando os "povos da floresta" carecedores de informação, comunicação e desprezados do seu processo de evolução. Esse tipo de ação vai além de suas próprias prioridades enquanto gestor e responsável pela efetivação dos direitos informativos e comunicacionais daquela sociedade, ao passo que não externa qualquer incentivo para empresas privadas efetivarem a instalação e manutenção do serviço.

Sobre a ação do governo amazonense, são as palavras de Fonseca ${ }^{32}$ :

Historicamente o norte do país é a região que menos possui cobertura de telecomunicações, isto é, serviço de telefonia fixa, celular, fibra óptica e acesso a internet. A deficiência deve-se ao fato de alto custo tecnológico de investimentos para a consolidação do setor na região. Argumento este apresentado, sobretudo, pelas empresas privadas de telecomunicações que atuam na Amazônia com a autorização do governo federal e da Agência Nacional de Telecomunicações (Anatel).

\footnotetext{
${ }^{31}$ MOURA, Ricardo Damasceno. Múltiplos saberes da diversidade em rede: conexões interculturais no debate da inclusão digital. Inc. Soc., Brasília, v. 5, n. 2, p. 62-72, jan./jun. 2012, p. 50.

32 FONSECA, Luca Milhomens. Ciberativismo na Amazônia: os desafios da militância digital na floresta (2012). In: SILVEIRA, Sérgio Amadeu da; BRAGA, Sérgio; PENTEADO, Cláudio. Cultura, política e ativismo nas redes digitais. São Paulo: Fundação Perseu Abramo, 2014, p. 59.
} 
Com o início do século XXI e os avanços tecnológicos da época iniciou-se a primeira tentativa infundada de levar Banda Larga para a Amazônia. De acordo com Fonseca (2014), apenas $20 \%$ da população tinha acesso à Internet, o que inviabilizava uma participação mais efetiva da sociedade junto às novas mídias. $\mathrm{O}$ autor registra ainda que, por conta disso, a utilização de blogs como instrumento de comunicação registrou suas primeiras postagens somente no ano de 2007.

Já no ano de 2010, o governo federal lançou o Plano Nacional de Banda Larga (PNBL), o qual tinha como objetivo levar Internet de alta velocidade para 40 milhões de domicílios em todo o Brasil até o ano de 2014. No entanto, com a desigualdade do acesso à Internet ente as regiões brasileiras, em especial a região Norte, o plano acabou por não atingir com efetividade a região amazônica.

De acordo com o relatório da pesquisa realizada pelo Cetic (CENTRO DE ESTUDOS SOBRE AS TECNOLOGIAS DA INFORMAÇÃO E DA COMUNICAÇÃO CETIC, 2013) $)^{33}$, apenas $26 \%$ da região Norte tem acesso à Internet, corroborando assim para a comprovação de que a Amazônia vive hoje a obscuridade de uma "exclusão digital". Ademais, cabe ressaltar que diante das informações acima citadas, o percentual de inclusão digital aumentou apenas 6\% em quatorze anos, uma proporção mínima tendo em vista o avanço da Internet e das novas tecnologias a nível mundial.

Recentemente, no ano de 2015, o Ministério da Defesa deu início ao programa intitulado "Amazônia Conectada", o qual visa criar uma infraestrutura de fibra ótica no interior do Amazonas e levar conectividade em alta velocidade para aquela região. A expectativa é possibilitar aos "povos da floresta" uma série de serviços de redes de dados com a mesma qualidade de Manaus, que vai além da Internet, ao passo que levará projetos como Telemedicina, Universidade a Distância e Interconexão entre Saúde, Segurança Pública, Trânsito e Turismo. No entanto, o projeto que tinha como data de inauguração para fins de ensaio 25 de maio daquele ano, foi cancelado ${ }^{34}$.

Logo, é nesse contexto, de que a inclusão digital na Amazônia tem um grande caminho a ser percorrido, que a presente pesquisa passa a abordar como os movimentos sociais engajados na luta pela implementação das Tecnologias da

33 CETIC - Centro de Estudos sobre as Tecnologias da Informação e Comunicação. Pesquisa TIC domicílios, 2013. Disponível em: < http://cetic.br/media/analises/tic-domicilios-2013.pdf> . Acesso em: 28 jun. 2015.

${ }^{34}$ AMAZÔNIA CONECTADA. Programa Amazônia conectada. Disponível em: < http://www.amazoniaconectada. eb.mil.br/> . Acesso em: 28 jun. 2015. 
Informação e Comunicação estão se organizando ao lado dos "povos da floresta", a fim de garantir e proteger sua cultura, seus direitos e suas terras por meio do ciberativismo.

Conforme Cavalcante ${ }^{35}$, o ciberativismo surgiu com o advento da Internet na década de 1990 e, com a popularização desta, ganhou visibilidade juntamente com o movimento Zapatista do México em 1994. Contudo, se fortaleceu a partir dos protestos antiglobalização em Seattle em 1999 e com a entrada de ONGs no ciberespaço.

Em um contexto evolutivo e conceitual, Milhomens ${ }^{36}$ define:

O ciberativismo surgiu após a popularização da internet através da Web, no início dos anos 1990 [...]. A rapidez, articulação e velocidade que as informações levam para chegar em todo o planeta despertou a atenção e interesse de inúmeros setores da sociedade, incluindo aí os militantes de vários campos de atuação. Estes mesmos setores começaram a fazer uso dessa tecnologia comunicacional e, enfim, criaram o termo ciberativismo. Ou seja, a militância exercida através das tecnologias digitais e da internet, presentes no mundo ciberespacial.

Nesta senda, Touraine ${ }^{37}$ define os movimentos sociais como "aqueles que combinam um conflito social com um projeto cultural e que defendem um modo diferente de uso dos valores morais". Segundo Castells ${ }^{38}$, hodiernamente os movimentos sociais do século XXI manifestam-se cada vez mais a partir da Internet e que essa tornou-se muito mais do que um instrumento e sim um meio de comunicação e organização para que esses movimentos aconteçam e os anseios de seus atores sejam ouvidos.

Desse modo, com vistas ao objetivo principal do presente tópico, registra-se que o ativismo digital na Amazônia está relacionado a um conjunto de insatisfação que busca dar visibilidade a uma causa comum, qual seja, a proteção do meio ambiente em que vivem. Ademais, com o mesmo entendimento de Touraine, Castells $^{39}$ informa que um dos motivos que move a militância está relacionado ao

\footnotetext{
35 CAVALCANTE, Rebeca Freitas. Ciberativismo: como as novas formas de comunicação estão a contribuir para a democratização da comunicação. Dissertação (Mestrado em Ciências da Comunicação) - Especialização em estudo dos media e do jornalismo da Universidade Nova de Lisboa, 2010, p. 37.

${ }^{36}$ MILHOMENS, Lucas. Entendendo o ciberativismo sem terra na nova esfera pública interconectada. Dissertação (Mestrado) - Universidade Federal da Paraíba, 2009, p. 65.

${ }^{37}$ TOURAINE, Alain. Podemos viver juntos?: iguais e diferentes. Petrópolis: Vozes, 2003, p. 119.

${ }^{38}$ CASTELLS, Manoel. A política da internet I: redes de computadores, sociedade civil e o Estado. In: A GALÁXIA da internet. Trad. Maria Luiza X. de A. Borges. Rio de Janeiro: Zahar, 2003, p. 114.

${ }^{39}$ CASTELLS, Manoel. O poder da identidade. São Paulo: Paz e Terra, 1999, p. 24-25.
} 
"poder da identidade", o qual reorganiza social e modernamente uma sociedade sob a égide de sua cultura e tradição identitária.

Nesse sentido, o ciberativismo praticado pelos "povos da floresta" busca o resgate de seus valores culturais, econômicos e políticos, sobretudo a forma como administravam suas terras nos primórdios da colonização, de maneira fértil e sustentável sem qualquer degradação de sua ambiência, engajados no que Castells ${ }^{40}$ denomina "identidade de resistência".

Sobre o fenômeno acima citado, são as palavras de Castells ${ }^{41}$ :

Criada por atores que se encontram em posições/condições desvalorizadas e/ou estigmatizadas pela lógica da dominação, construindo, assim, trincheiras de resistência e sobrevivência com base em princípios diferentes dos que permeiam as instituições da sociedade, ou mesmo opostos a estes últimos [...]. É provável que seja esse o tipo mais importante de construção de identidade em nossa sociedade. Ele dá origem a formas de resistência coletiva diante de uma opressão que, do contrário, não seria suportável, em geral com base em identidades, que, aparentemente, foram definidas com clareza pela história, geografia, ou biologia, facilitando assim a "essencialização" dos limites de resistência.

Ainda, cabe aqui uma breve reflexão baseada no que Moura ${ }^{42}$ chama de "Etnologia da Cibercultura", ou seja, que o uso das TICs pelos "povos da floresta" não deve tratar somente a cultura material de um povo determinado e, sim, que possa propiciar uma integração entre grupos culturais distintos e, consequentemente, aumentar a rede de atores digitais engajados por objetivos em comum.

Nesse contexto, Lévy ${ }^{43}$ fala em inteligência coletiva, onde essa interação e distribuição de informações por grupos individualizados, porém conectados, resulta em uma mobilização efetiva de movimentos que buscam, além de uma satisfação, o reconhecimento de sua cultura, identidade e aspirações.

Portanto, para Moura ${ }^{44}$ :

[...] uma cibercultura pautada na Etnologia alerta para as condições entre as possibilidades do reconhecimento do saber tradicional em

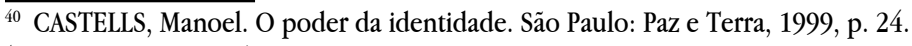

${ }^{41}$ Ibidem, 1999, p. 24-25.

${ }^{42}$ MOURA, Ricardo Damasceno. Inclusão digital e a busca por um acesso tecnológico respaldado nos reais interesses dos povos da Amazônia. Revista de ciência, tecnologia e inovação do estado do Pará, 2012, p. 50. Disponível em: < http://veraciencia.pa.gov.br/upload/arq_arquivo/83.pdf > . Acesso em: 20 jun. 2015.

${ }^{43}$ LÉVY, Pierre. Ciberdemocracia. Lisboa: Instituto Piaget, 2002, p. 50.

${ }^{44}$ MOURA, op cit., 2012, p. 50. 
rede, favorecendo a troca de conhecimentos e a efetiva participação pública de populações da Amazônia nas tomadas de decisão em prol da sustentabilidade do meio ambiente.

Diante do exposto, tendo em vista os argumentos elencados no texto que comprovam a importância da inclusão digital sobre o aspecto do ciberativismo interligado à cibercultura, resta a exemplificação de um movimento social que se organiza por meio das Tecnologias da Informação e Comunicação objetivando a defesa de uma tradição colonizadora e engajada na proteção do seu meio ambiente.

Nesta senda, diante do objetivo principal do presente trabalho, o movimento social/digital aqui analisado trata-se da "Rede Povos da Floresta". Fundada no ano de 2003 foi um dos primeiros movimentos a se organizar em prol de interesses comuns relacionados às tradições, cultura, território e proteção do meio ambiente amazônico. Embasada nos ideais de Chico Mendes, o movimento originário do Estado do Acre excluiu sua página oficial na Web e hoje sua forma de interação com as comunidades tradicionais e indígenas é por meio de sua página na rede social de relacionamento Facebook.

No item missão, a Rede Povos da Floresta ${ }^{45}$ externa suas ações e objetivos:

\begin{abstract}
A Rede Povos da Floresta investe na infra-estrutura de comunicação e informação, inclusão digital e intercâmbio entre os diversos povos tradicionais e em recursos como georreferenciamento, radiofonia e acesso à internet, que proporcionam condições favoráveis para a defesa do território e agilidade para a realização de denúncias contra práticas exploratórias ilegais ou abusivas. As comunidades conectadas pela internet via satélite utilizam as facilidades da Rede para articular projetos, trocar informações com seus aliados e órgãos competentes e ainda beneficiam-se dos serviços por ela oferecidos. A vigilância e o monitoramento passam a ser realizados pelos próprios moradores, tornando-os soberanos em seus territórios e protagonistas em sua área de atuação.
\end{abstract}

O destaque para tal movimento está na sua própria produção de conteúdo audiovisual, os quais são mostrados em curtas e longas metragens indígenas em diferentes regiões da Amazônia. A foto que estampa a sua página no Facebook demonstra um grupo de indígenas e demais "povos da floresta" em curso de capacitação em Áudiovisual. Os vídeos ficam dispostos na página oficial chamada

\footnotetext{
${ }^{45}$ REDE POVOS DA FLORESTA. Disponível em: < https://www.facebook.com/pages/Rede-Povos-da-Floresta/224
} 531120943649?sk=timeline > . Acesso em: 28 jun. 2015. 
"Vídeo nas Aldeias". O site, criado em 1986, é um projeto na área da produção audiovisual indígena no Brasil e tem como objetivo as lutas dos povos indígenas, o fortalecimento de suas culturas e identidades e a proteção de seus patrimônios territoriais ${ }^{46}$.

Navegando pelo site, no link catálogos, é possível visualizar uma grande quantidade de vídeos protagonizados pelos povos indígenas em defesa do meio ambiente em que vivem. Um desses vídeos feitos exclusivamente para a Conferência das Nações Unidas sobre o Desenvolvimento Sustentável - RIO+20 foi filmado por uma mulher indígena pertencente à tribo Kisêdjê, chamada Kamikia Kisêdjê, a qual produziu uma mensagem em nome do seu povo expressando sua apreensão com relação à devastação da Amazônia e ao futuro dos seus netos.

Em um primeiro momento, o vídeo mostra a protagonista externando sua tristeza com o povo que ela chama de "brancos" por estarem terminando com suas terras e com o alimento do seu povo. Nesse contexto, ela filma mães e crianças procurando frutos para se alimentar, sendo que só encontram pela frente o desmatamento. Na mesma oportunidade, ela mostra o relato de uma dessas mães que pede para que os homens tirem as máquinas daquele território e parem de poluir os rios e as nascentes de onde vem a água que mata sua sede e que banha a sua tribo.

Em um segundo momento, um homem indígena fala sobre $\mathrm{o}$ alto número de queimadas naquela região, ele diz que a fumaça aumenta a cada dia, mas é apenas o povo indígena que se preocupa com essa situação. Ele diz que o homem branco gosta das queimadas, pois além de derrubar sua mata e abrir caminhos para as máquinas, é a partir delas que suas árvores são transformadas em industrialização.

No final do vídeo ela filma o ritual de comemoração dos 50 anos do parque indígena do Xingu, onde inúmeros líderes de diversas tribos se uniram em defesa dos seus direitos e principalmente na defesa de suas terras. Dentre as colaborações por parte dos representantes registra-se uma frase que resume a luta daqueles povos e os seus anseios frente à preservação do meio ambiente ${ }^{47}$.

Quando todos os rios secarem, os filhos de vocês vão morrer de sede, é o que eu tenho para falar pra vocês brancos. Vocês pensam que estão fazendo uma coisa para a sua sobrevivência,

\footnotetext{
${ }_{46}$ VÍDEO NAS ALDEIAS. Carta Kisêdjê para a RIO+20 Amne Adji papere MBA. Disponível em: <http://www. videonasaldeias.org.br/2009/video.php?c $=103>$. Acesso em: 28 jun. 2015.

47 VÍDEO NAS ALDEIAS. Carta Kisêdjê para a RIO+20 Amne Adji papere mba. Disponível em: <http://www. videonasaldeias.org.br/2009/video.php?c $=103>$. Acesso em: 28 jun. 2015.
} 
mas estão destruindo a si mesmos! Se vocês estão a favor disso, vocês que sabem... se querem morrer, continuam destruindo, aí morremos todos juntos!

Logo, percebe-se que o ativismo da Rede Povos da Floresta, além de movimentar-se socialmente através do ciberativismo na rede, proporciona que os próprios sujeitos de direitos possam externar a partir do uso das TICs sua resistência contra o capitalismo que assombra a cultura e o território do seu povo. Desse modo, o movimento ganha voz e visibilidade, sua transmissão para a RIO+20 no ano de 2012 foi a prova de que a inclusão digital na Amazônia faz-se necessária para a busca e efetividade dos direitos identitários daquele povo e preservação de sua floresta.

Desse modo, conclui-se que apesar de a inclusão digital não abranger homogeneamente os "povos da floresta", o ciberativismo dirigido por atores de dentro e de fora daquele território está possibilitando um novo tipo de integração e exposição dos anseios daquela população que luta pelo mesmo bem comum, o meio ambiente. Ademais possibilita uma abordagem de temas que por hora eram obscuros ou inexistentes nas mídias tradicionais e, desse modo, busca tornar os "povos da floresta" conhecedores de seus direitos e que esses, a partir do ciberativismo, possam resistir à opressão do Estado e continuar na luta, de maneira especial pelas suas terras e sua identidade.

\section{CONCLUSÃO}

Em sede de apontamentos conclusivos, é necessário referenciar acerca do uso das novas tecnologias informacionais e a ampliação do espaço público de questões que pertinem à coletividade, a troca e o acesso a novos conteúdos noticiosos e informacionais vêm remodelando a sociedade contemporânea na medida em que permitem ao cidadão comum expressar sua opinião, criar, editar e difundir informações. Nesse ínterim rompe-se totalmente com a lógica unidirecional da grande mídia que tem por base a comunicação centralizada e baseada apenas no emissor, sem a possibilidade de conversação entre os usuários.

A sociedade informacional, ou seja, aquela forma social definida por Castells que tem no cerce a informação como motriz principal, reconfigura o espaço da malha social, empoderando o cidadão e permitindo-lhe a efetivação de direitos e 
a consecução de demandas essenciais à sua vida. Nesse contexto, o primeiro eixo encarregou-se de explanar acerca da revolução provocada pelas Tecnologias da Informação e Comunicação, sobretudo aquelas calcadas na Internet, edificando a sociedade informacional, de modo a garantir o amplo acesso a informaçóes quando se trata de matéria ambiental, exasperando os conteúdos ecológicos acerca do panorama ecológico atual. Esse processo crescente de compartilhamento de informações na Internet vem gerando expressivas mudanças, também no que diz respeito às relações de poder na atualidade, tal mudança favorece o surgimento de uma (re)politização da sociedade na medida em que propicia novos olhares para os fatos e amplia o espaço de crítica e discussão sobre as questões ambientais.

Também fora alvo de visualização no presente ensaio o papel da jurisdição, como um efetivo instrumento de consecução de direitos e balizador de demandas processuais. Neste mote, fora reverberado sobre a utilização da jurisdição como ferramenta de promoção de um meio ambiente ecologicamente equilibrado, renegando a sua concepção econômica e liberal-individualista que até então se mostra presente. Neste contexto, prescindiu-se a necessidade de uma jurisdição em total compasso com os ditames e prerrogativas expostas e solidificadas na Constituição Federal de 1988.

O segundo ponto explorado no artigo refere acerca do cenário observado na região Norte e Nordeste do país que sofre à margem dos Estados, do Governo Federal e das instituições e empresas da iniciativa privada que não incrementam ou destinam investimentos em recursos tecnológicos para propiciar a utilização da Internet, é o caso dos excluídos digitais da Amazônia. No mesmo ponto fora explorado o ciberativismo realizado pelos povos amazonenses, o que reverbera a luta por direitos e garantias fundamentais, além de propiciar uma visualização da envergadura das tecnologias informacionais na consecução de direitos e efetivação de demandas.

Desta feita, apesar do grande impacto causado pelas Tecnologias da Informação e Comunicação na sociedade contemporânea, deve-se ter consciência de que esta ágora virtual, que consiste em um espaço profícuo para debate de questões e acesso a informações, ainda está chancelada a um restrito e diminuto grupo de pessoas que possuem acesso à Internet e a tais tecnologias, de modo que também possuem habilidade para saber utilizar todas as potencialidades ofertadas por essas ferramentas. De qualquer forma, não há como negar o fenômeno da virtualidade e 
da convergência digital, que revoluciona a interação entre os cidadãos, deslocandoos do polo passivo e apontando-os como interlocutores com o poder público, expressando suas opiniões e ideias, especialmente sobre matérias de interesse coletivo, como a ambiental e de sustentabilidade, como referido no presente artigo.

\section{REFERÊNCIAS}

AMAZÔNIA CONECTADA. Programa Amazônia conectada. Disponível em: < http:// www.amazoniaconectada.eb.mil.br/> . Acesso em: 28 jun. 2015.

BRASIL. Constituição (1988). Constituição da República Federativa do Brasil: promulgada em 05 de outubro de 1988. Brasília: Senado Federal. Disponível em: $<$ http://www.planalto.gov.br/ccivil_03/constituicao/constituicaocompilado.htm>. Acesso em: 31 mai. 2015.

AMAZÔNIA CONECTADA. Lei 12.527 de 18 de novembro de 2011. Regula o acesso a informações previsto no inciso XXXIII do art. $5^{\circ}$, no inciso II do $\S 3^{\circ}$ do art. 37 e no $\S 2^{\circ}$ do art. 216 da Constituição Federal; altera a Lei n⿳0 8.112 , de 11 de dezembro de 1990; revoga a Lei oㅗ 11.111, de 05 de maio de 2005, e dispositivos da Lei ํㅡㅇ 8.159, de 08 de janeiro de 1991; e dá outras providências. Disponível em: < http://www. planalto.gov.br/ccivil_03/_ato2011-2014/2011/lei/12527.htm >. Acesso em: 31 mai. 2015.

BERNARDES, Marciele Berger. Democracia na sociedade informacional: o desenvolvimento da democracia digital nos municípios brasileiros. São Paulo: Saraiva, 2013.

CANCLINI, Nestor García. Leitores, espectadores e internautas. Tradução de Ana Goldberger. São Paulo: Iluminuras, 2008.

CARDOSO, Antônio Alexandre Isidio. Os migrantes cearenses e o horizonte amazônico no século XIX. Revista de História, v. 4, n. 1, p. 68-87, 2012. Disponível em: < http://www.revistahistoria.ufba.br/2012_1/a04.pdf>. Acesso em: 28 jun. 2015. 
CASTELLS, Manuel. A sociedade em rede - a era da informação: economia, sociedade e cultura. 5. ed. Traduzido por Klauss Brandini Gerhardt e Roneide Venancio Majer. São Paulo: Paz e Terra, 1999.

CASTELLS, Manuel. O poder da identidade. São Paulo: Paz e Terra, 1999.

CASTELLS, Manuel. A política da internet I: redes de computadores, sociedade civil e o Estado. In: A galáxia da internet. Trad. Maria Luiza X. de A. Borges. Rio de Janeiro: Zahar, 2003.

CAVALCANTE, Rebeca Freitas. Ciberativismo: como as novas formas de comunicação estão a contribuir para a democratização da comunicação. Dissertação (Mestrado em Ciências da Comunicação) - Especialização em estudo dos media e do jornalismo da Universidade Nova de Lisboa, 2010.

CETIC - Centro de Estudos sobre as Tecnologia da Informação e Comunicação. Pesquisa TIC domicílios, 2013. Disponível em: < http://cetic.br/media/analises/ticdomicilios-2013.pdf> . Acesso em: 28 jun. 2015.

CORREAA, Roberto Lobato. A organização regional do espaço brasileiro: redes eletrônicas e novas dinâmicas do território brasileiro. In: CASTRO; GOMES; CORRÊA, 1995.

DUPAS, Gilberto. Ética e poder na sociedade da informação: de como a autonomia das novas tecnologias obriga a rever o mito do progresso. 2. ed. Rev. Ampliada. São Paulo: UNESP, 2011.

ESPÍNDOLA, Ângela Araujo da Silveira. A refundação da jurisdição e as multidimensões da sustentabilidade. In: TYBUSCH, Jerônimo Siqueira; ARAUJO, Luiz Ernani Bonesso de; SILVA, Rosane Leal da (Org.). Direitos emergentes na sociedade global: anuário do Programa de Pós-Graduação em Direito da UFSM. Ijuí: Unijuí, 2013, p. 49-74.

FREITAS, Marilene Côrrea da Silva. Políticas públicas, territórios, populações tradicionais e ambiente na Amazônia. In: OLIVEIRA, José Admir de; SCHERER, Elenice (Org.). Amazônia: territórios, povos tradicionais e ambiente. Manaus: Adua, 2009, p. 23-24. 
FONSECA, Luca Milhomens. Ciberativismo na Amazônia: os desafios da militância digital na floresta (2012). In: SILVEIRA, Sérgio Amadeu da; BRAGA, Sérgio; PENTEADO, Cláudio. Cultura, política e ativismo nas redes digitais. São Paulo: Fundação Perseu Abramo, 2014.

GONÇALVES, Maria Eduarda. Direito da informação: novos direitos e formas de regulação na sociedade da informação. Coimbra: Almedina, 2003.

GREENPEACE BRASIL. Amazônia: patrimônio brasileiro futuro da humanidade. Disponível em: < http://www.greenpeace.org/brasil/pt/O-que-fazemos/Amazonia/>. Acesso em: 28 jun. 2015.

INSTITUTO BRASILEIRO DE GEOGRAFIA E ESTATÍSTICA. IBGE. Mapa integrado dos zoneamentos ecológico-econômicos dos estados da Amazônia Legal. Disponível em: < http://www.ibge.gov.br/home/geociencias/geografia/mapas_doc5. shtm $>$. Acesso em: 28 jun. 2015.

LÉVY, Pierre. Ciberdemocracia. Lisboa: Instituto Piaget, 2002.

LÉVY, Pierre. A inteligência coletiva: por uma antropologia do ciberespaço. São Paulo: Record, 1998.

LUÑO, Peres. Ciberciudadaní@ o ciudadaní@.com? Barcelona: Gedisa, 2004.

MATTELART, Armand. La Mundializacíon de la comunicacíon. Tradução de Orlando Carreño. Barcelona: Paidós, 1998.

MILHOMENS, Lucas. Entendendo o ciberativismo sem terra na nova esfera pública interconectada. 2009. Dissertação (Mestrado) - Universidade Federal da Paraíba, 2009.

MOURA, Ricardo Damasceno. Múltiplos saberes da diversidade em rede: conexões interculturais no debate da inclusão digital. Inc. Soc., Brasília, v. 5, n. 2, p. 62-72, jan./jun. 2012.

MOURA, Ricardo Damasceno. Inclusão digital e a busca por um acesso tecnológico respaldado nos reais interesses dos povos da Amazônia. Revista de ciência, tecnologia e inovação do estado do Pará. 2012, p. 50. Disponível em: < http:// veraciencia.pa.gov.br/upload/arq_arquivo/83.pdf> . Acesso em: 20 jun. 2015. 
FERNANDES NETO, Guilherme. Direito da Comunicação Social. São Paulo: Revista dos Tribunais, 2004.

NUNES, Denise Silva; DAVIES, Lorenice Freire. A imprescindibilidade de ressignificar a jurisdição em prol da sustentabilidade: estratégias contra a racionalidade. Revista Eletrônica Direito e Política, Itajaí, v.10, n. 1, edição especial de 2015. Disponível em: <http://www.univali.br/direito e política > Acesso em: 30 mai. 2015.

ORGANIZAÇÃO DAS NAÇÕES UNIDAS . ONU. Declaração do Rio sobre Meio Ambiente e Desenvolvimento. Publicada em 1992. Disponível em: < http://www. onu.org.br/rio20/img/2012/01/rio92.pdf. > . Acesso em: 30 mai. 2015.

ORGANIZAÇÃO DAS NAÇÕES UNIDAS (ONU). Agenda 21 Global. Publicada em 1992. Disponível em: <http://www.meioambiente.pr.gov.br/arquivos/File/ agenda_21_Global_Integra.pdf. $>$. Acesso em: 30 mai. 2015.

RECUERO, Raquel. Redes sociais na internet. Porto Alegre: Sulina, 2009.

REDE POVOS DA FLORESTA. Disponível em: < https://www.facebook.com/pages/ Rede-Povos-da-Floresta/224531120943649?sk=timeline > . Acesso em: 28 jun. 2015.

SANCHES, Oscar Adolfo. Governo Eletrônico no Estado de São Paulo. São Paulo, 2003. (Série didática n. 7).

TOURAINE, Alain. Podemos viver juntos?: iguais e diferentes. Petrópolis: Vozes, 2003.

VÍDEO NAS ALDEIAS. Carta Kisêdjê para a RIO+20 Amne Adji papere mba. Disponível em: <http://www.videonasaldeias.org.br/2009/video.php?c=103>. Acesso em: 28 jun. 2015.

VOLKMER, André. A democracia na era digital. In: INSTITUTO DE ESTUDOS EMPRESARIAIS. Liberdade na era digital. Porto Alegre: IEE, 2011, p. 90-109.

Recebido em: 31 de agosto de 2015 Aceito em: 20 de julbo de 2016 